\title{
Physician Beliefs about the Meaningful Use of the Electronic Health Record: A Follow-Up Study
}

\author{
Srinivas Emani ${ }^{1}$ David Y. Ting ${ }^{2}$ Michael Healey ${ }^{1,3}$ \\ David W. Bates ${ }^{1,5}$ \\ 2 Massachusetts General Physicians Organization, Massachusetts \\ General Hospital, Boston, Massachusetts, United States \\ 3 Brigham and Women's Physicians Organization, Brigham and \\ Women's Hospital, Boston, Massachusetts, United States \\ ${ }^{4}$ Decision Support Unit, Massachusetts General Hospital, Harvard \\ Medical School, Boston, Massachusetts, United States \\ ${ }^{5}$ Department of Healthcare Policy and Management, Harvard School \\ of Public Health, Boston, Massachusetts, United States \\ Appl Clin Inform 2017;8:1044-1053.
}

Stuart R. Lipsitz ${ }^{1}$ Andrew S. Karson ${ }^{4}$

Address for correspondence Srinivas Emani, PhD, Division of General Internal Medicine, Department of Medicine, Brigham and Women's Hospital, Harvard Medical School, 1620 Tremont Street, Third Floor, Boston, MA 02120, United States (e-mail: semani1@partners.org).

\section{Abstract}

Keywords

- electronic health records

- physicians

- beliefs

- meaningful use

- self-efficacy
Background There is continuing interest in how physicians are responding to the meaningful use of the electronic health record (EHR) incentive program. However, little research has been done on physician beliefs about the meaningful use of the EHR.

Objective This study aims to conduct a follow-up study of physician beliefs about the meaningful use of the EHR.

Methods Online survey of physicians at two academic medical centers (AMCs) in the northeast who were participating in the meaningful use of the EHR incentive program and were using an internally developed EHR was conducted.

Results Of the 2,033 physicians surveyed, 1,075 completed the survey for an overall response rate of $52.9 \%$. Only one-fifth $(20.5 \%)$ of the physicians agreed or strongly agreed that meaningful use of the EHR would help them improve quality of care, and only a quarter (25.2\%) agreed or strongly agreed that the meaningful use of the EHR would improve the care that their organization delivers. Physician satisfaction with the outpatient EHR was the strongest predictor of self-efficacy with achieving stage 2 of the meaningful use of the EHR incentive program (odds ratio: $2.10,95 \%$ confidence interval: $1.61,2.75, p<0.001)$. Physicians reported more negative beliefs in stage 2 than stage 1 across all belief items. For example, 28.1\% agreed or strongly agreed that the meaningful use of the EHR would decrease medical errors in stage 2 as compared with $35.9 \%$ in stage $1(p<0.001)$.

Conclusion Only one-fifth of the physicians in our study believed that the meaningful use of the EHR would improve quality of care, patient-centeredness of care, or the care they personally provide. Primary care physicians expressed more negative beliefs about the meaningful use of the EHR in stage 2 than in stage 1. These findings show that physicians continue to express negative beliefs about the meaningful use of the EHR. These ongoing negative beliefs are concerning for both implementation and policy. received

May 15, 2017

accepted after revision

August 31, 2017
Copyright @ 2017 Schattauer

August 31,2017 


\section{Background and Significance}

The objectives of the Medicare and Medicaid Electronic Health Record (EHR) Incentive Program, also widely referred to as the meaningful use of the EHR incentive program, are to increase the adoption of EHRs and the meaningful use of EHRs to improve delivery of care, decrease medical errors, improve efficiency of care, and enhance patient-centeredness of care. ${ }^{1,2}$ In the context of the meaningful use of the EHR incentive program, there has been growing interest among clinical informatics researchers in evaluating the impact of EHR use. This evaluation can be objective, for example, through outcomes such as quality measures.,

Another approach is to focus on perceptions and beliefs about the meaningful use of the EHR. One qualitative study explored perceptions of academic and private physicians about the impact of EHR use on workflow and patient care. ${ }^{5}$ The study did not find differences in perceptions between these two groups but both had negative perceptions of the impact of EHR on workflow and patient care. The same researchers reported that super-user physicians (physicians who were product champions) had similar negative perceptions. ${ }^{6}$ Weeks et al compared perceptions of the impact of EHR use in two groups of physicians users (active vs. inactive) of the meaningful use of the EHR incentive program. ${ }^{7}$ They found that even in the active, meaningful user group a majority of physicians disagreed about the impact of meaningful use on reducing care disparities (78\% disagreed) and improving the accuracy of patient information (70\% disagreed). In a previous study, we found that a majority of physicians had negative beliefs about the meaningful use of the EHR. ${ }^{8}$ For example, only 23 and $27 \%$ of physicians in our study agreed or strongly agreed that the meaningful use of the EHR would help them improve the care they personally deliver and improve quality of care, respectively. We also found negative physician beliefs about a specific functionality of the EHR, the provision of the after visit summary (AVS). ${ }^{9}$ In this study, $79.2 \%$ of primary care physicians and $75.2 \%$ of specialists reported that generating and providing the AVS had an adverse effect on physician workload.

\section{Objective}

The objective of this study was to assess physician beliefs about the meaningful use of the EHR. To achieve this objective, we conducted a follow-up survey using items which we had developed in a previous study. ${ }^{8}$ A secondary objective was to assess physician self-efficacy for achieving stage 2 of the meaningful use of the EHR incentive program and the predictors of self-efficacy.

\section{Methods}

\section{Context}

The context for this study is stage 2 of the meaningful use of the EHR incentive program, introduced in the Health Information Technology for Economic and Clinical Health (HITECH) provision of the American Recovery \& Reinvestment Act of 2009. 1,2,10-12 The meaningful use incentive program was originally designed to take place over three stages from 2011 through 2016 . $^{2}$ Stage 1 focused on the collection of discrete or coded health information. Stage 2 was intended to see the leveraging of those data for computerized decision support. Stage 3 anticipated actual improvement in clinical care, based on the use of data in the EHR. For such achievement, maintained over the three-stage life of the incentive program, eligible professionals (EPs) could receive up to $\$ 44,000$ (Medicare) or $\$ 63,750$ (Medicaid). Furthermore, EPs who failed to achieve meaningful use would see a reduction of their CMS (Centers for Medicare \& Medicaid Services) payments beginning at $1 \%$ of total payments, with penalties increasing by $1 \%$ per year afterward.

This staged approach to the meaningful use of the EHR incentive program has been considered analogous to the concept of an escalator. ${ }^{1}$ With each stage, the notion has been that providers would move upward toward the final goal of achieving improvement in quality, safety, and efficiency of care. ${ }^{2}$ At the same time, proponents of the program acknowledged the need for calibrating the speed of the escalator to account for technological and resource limitations in the real world. ${ }^{1}$

\section{Participants}

The participants in this study were physicians at two academic medical centers (AMCs) in the northeast who were participating in the meaningful use of the EHR incentive program. With respect to the AMCs, AMC1 is a 777-bed medical center with 57,000 admissions per year and AMC2 is a 907-bed medical center with 48,000 admissions per year. AMC1 has 101 affiliated outpatient practices with 170 primary care physicians, 1,423 specialists, and 769,000 outpatient visits a year. AMC2 has 175-affiliated outpatient practices, with 259 primary care physicians, 1,737 specialists, and 1.5 million outpatient visits a year. At both AMCs, a common home-grown outpatient EHR was in use when this study was conducted. The home-grown EHR was an internally developed, web-based, fully functioning EHR that included notes from primary care and subspecialty clinics; hospital discharge summaries; International Classification of Diseases, Ninth Revision-coded problem lists; health maintenance lists; medication prescribing; coded allergies; laboratory and radiographic results; and result management. The adoption and use rate of the outpatient EHR by physicians was $100 \%$ across both AMCs as it is a requirement for affiliation with the AMCs.

\section{Survey Instrument}

In a previous study, we described the development of our survey instrument. ${ }^{8}$ We adopted the same belief items from that study for this survey. We conceptualized beliefs as outcome expectancies, and as a result, our belief items focus on the meaningful use of the EHR for decreasing medical errors, increasing efficiency of care, and improving patientcenteredness and quality of care. The belief items were captured as five-point Likert scales ranging from strongly disagree to strongly agree ( - Table 1 ).

In addition to beliefs, we assessed self-efficacy for achieving stage 2 of the meaningful use of the EHR incentive program. Self-efficacy was captured as the degree of confidence physicians have in achieving stage 2 and measured on a Likert scale 
Table 1 Items on beliefs about the meaningful use of the EHR

\begin{tabular}{|l|}
\hline Meaningful use will improve the quality of care I deliver \\
\hline $\begin{array}{l}\text { Meaningful use will improve the patient-centeredness } \\
\text { of care I provide }\end{array}$ \\
\hline $\begin{array}{l}\text { Meaningful use will not increase the efficiency of care } \\
\text { I provide }\end{array}$ \\
\hline $\begin{array}{l}\text { Meaningful use will not lead to improved patient } \\
\text { outcomes }\end{array}$ \\
\hline Meaningful use will decrease medical errors \\
\hline $\begin{array}{l}\text { Overall, I think meaningful use as being measured will } \\
\text { help me use the EHR to improve the care I personally } \\
\text { deliver }\end{array}$ \\
\hline $\begin{array}{l}\text { Overall, I think meaningful use as being measured will } \\
\text { help me use the EHR to improve the care the AMC delivers }\end{array}$ \\
\hline
\end{tabular}

Abbreviations: AMC, academic medical center; EHR, electronic health record.

Note: Response categories: Strongly disagree, disagree, neutral, agree, strongly agree.

( $1=$ not at all confident to $5=$ extremely confident). We also gathered data on factors identified in previous studies as influencing the adoption and meaningful use of the $\mathrm{EHR}^{8,9,13-16}$ : physician age, gender, race, specialty (primary care, medical specialty, and surgical specialty), number of outpatients seen per week, number of outpatient hours worked per week, practice size, and satisfaction with the outpatient EHR. We recorded physician age into two categories: Younger than 55 years and 55 years and older. We recorded satisfaction with the outpatient EHR into two categories: Satisfied (defined as satisfied or very satisfied) and other (defined as very dissatisfied or dissatisfied or somewhat dissatisfied or somewhat satisfied).

\section{Data Collection}

As described above in the section on participants, our subjects were physicians who were EPs at two AMCs participating in the meaningful use incentive program. We administered the survey using the tool "Survey Monkey." We sent the initial survey followed by three reminders. To enhance the response rate, we offered an Amazon tablet to 10 randomly drawn respondents.

\section{Statistical Analysis}

Because all variables of interest in our analysis are categorical, descriptive statistics are presented using percentages. We conducted bivariate analyses using the Pearson's chi-square test. A $p$ value of less than 0.05 was considered statistically significant. We employed logistic regression analysis to assess significant correlates of self-efficacy, our main outcome of interest. Our explanatory variables were all dichotomous (e.g., other vs. agree/strongly agree). In the model, we only included variables that were significant in our bivariate analyses. We entered all variables into the model rather than choose a forward or backward selection approach. The statistical significance of the covariates in the logistic regression model was evaluated using Wald's $p$ values. ${ }^{17}$ Finally, we analyzed whether beliefs about the meaningful use of the EHR changed from stage 1 to stage 2 of the meaningful use of the EHR incentive program. We conducted pairwise comparisons of the responses to the belief items from our survey on the meaningful use of the EHR conducted in 2012 with respect to stage 1 with those from this survey conducted in 2014 with respect to stage 2 . All analyses were completed using SPSS (IBM Corp.) for Windows 23.0.

\section{Institutional Review Board Approval}

Approval for the study was obtained from the Partners HealthCare Institutional Review Board.

\section{Results}

\section{Response Rates}

Of the 2,033 physicians at both AMCs participating in the meaningful use of the EHR incentive program, 1,075 completed the survey for an overall response rate of $52.9 \%$. There was no difference in age between responders and nonresponders: The mean age of survey responders was 50.66 years as compared with 50.74 years for nonresponders. Female physicians were more likely to respond to the survey: $55.9 \%$ were responders as compared with $44.1 \%$ of non-responders $(p=0.02)$. - Table 2 shows the demographic and practice characteristics of respondents.

\section{Beliefs about the Meaningful Use of the EHR}

Only one-fifth of respondents agreed or strongly agreed that meaningful use of the EHR would improve patient-centered care $(20.9 \%, n=223)$ and quality of care $(20.5 \%, n=217)$ ( - Table 3 ). Only a quarter of respondents $(25.2 \%, n=268)$ agreed or strongly agreed that meaningfully using the EHR will improve the care that their AMC delivers. Of the respondents, $62.9 \%$ (673) agreed or strongly agreed that the meaningful use of the EHR would not increase the efficiency of the care they provide.

Of the respondents, only $29 \%$ ( 311 of the 1,075 respondents) provided comments in an open-ended comment field. The comments were overwhelmingly negative and reflected the negative beliefs about the meaningful use of the EHR reported above. A common theme was physician concern about the amount of data entry required for the meaningful use of the EHR. As one physician commented: "Time consuming goals, not linked to improving outcomes for patients. Creates lots of work, mainly tapping on the computer while we should be talking to and examining patients." Another physician noted: "Meaningful use is focused on checking boxes that do not improve care and interfere with my ability to spend time talking with my patients. It puts the physician in the role of data entry technician." - Table 4 provides a sampling of the comments across different physician specialties.

With respect to demographic characteristics, physician age was not associated with beliefs about the meaningful use of the EHR ( - Table 5). Physician gender was also not associated with beliefs except the belief that meaningful use will not improve patient outcomes. Physician race was associated with beliefs that the meaningful use of the EHR will improve quality of care, the care the physician personally delivers, and the care the 
Table 2 Characteristics of respondents $(n=1,075)$

\begin{tabular}{|l|l|}
\hline $\begin{array}{l}\text { Physician and practice } \\
\text { characteristics }\end{array}$ & Percent \\
\hline Gender & 45.7 \\
\hline Female & 54.3 \\
\hline Male & 65.4 \\
\hline Age & 34.6 \\
\hline$<55$ y & 19.5 \\
\hline$\geq 55$ y & 80.5 \\
\hline Race & 19.2 \\
\hline Non-White & 66.1 \\
\hline White & 14.7 \\
\hline Specialty & \\
\hline Primary care & 56.9 \\
\hline Medical specialties & 43.1 \\
\hline Surgical specialties & 61.1 \\
\hline Hours worked outpatient & 56.5 \\
\hline$\leq 20$ h/wk & 43.5 \\
\hline$>20$ h/wk & 3.1 \\
\hline No. of outpatients per week & 10.6 \\
\hline$\leq 30$ & 25.2 \\
\hline$>30$ & \\
\hline Practice size & \\
\hline $1-2$ & \\
\hline $3-5$ & \\
\hline $6-10$ & 11 \\
\hline 2 & \\
\hline & \\
\hline
\end{tabular}

AMC delivers. Non-Caucasian physicians had more positive beliefs than Caucasian physicians. For example, 29.1\% of nonCaucasian physicians believed that meaningful use would improve the care they personally deliver compared with $19.3 \%$ of Caucasian physicians $(p=0.003$ ).

With respect to practice characteristics, physician specialty was strongly associated with the beliefs that the meaningful use of the EHR will decrease medical errors, will not improve patient outcomes, and will improve the quality of care ( - Table 5). Overall, $36.6 \%$ of primary care respondents agreed or strongly agreed that the meaningful use of the EHR would decrease medical errors compared with $31.2 \%$ of medical specialists and $19 \%$ of surgical specialists $(p=0.001)$. Also, $48 \%$ of surgical specialists agreed or strongly agreed that meaningful use would not improve patient outcomes compared with $37.0 \%$ of medical specialists and $31.5 \%$ of primary care physicians $(p=0.005)$.

The number of outpatient hours worked per week was not associated with the beliefs except for the belief that the meaningful use of the EHR will not increase the efficiency of care ( - Table 5). The number of outpatients seen per week was significantly associated with all the beliefs except the belief that the meaningful use of the EHR will improve

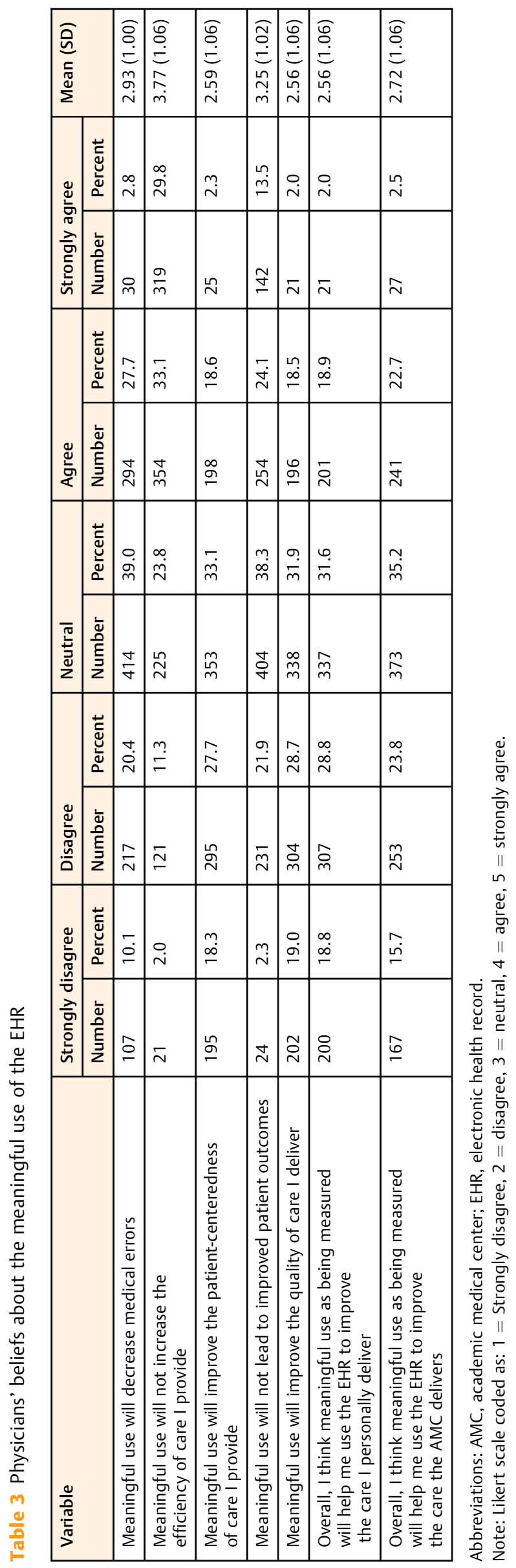


Table 4 Sampling of comments from physicians

\begin{tabular}{|c|c|}
\hline PCP & $\begin{array}{l}\text { Meaningful use demands computer-centered rather than patient-centered care. The first stage was } \\
\text { doable. I think the next will require many burdensome workarounds as I try to prove to others the patient } \\
\text { communication and follow-up I was doing anyway and now have time to do less well }\end{array}$ \\
\hline PCP & $\begin{array}{l}\text { Constantly demands workarounds. Alternatively, the scripted attestations that I have talked to my } \\
\text { patients about hypertension, etc. It has increased the amount of time involved with computer and } \\
\text { administration, is clunky in its implementation, and reduced the time available for patient care. If this } \\
\text { were a drug, it would never have cleared phase } 1 \text { trials. It could be worse, and I am sure it will be }\end{array}$ \\
\hline PCP & $\begin{array}{l}\text { As is often the case, too much time and effort are being dedicated to checking off boxes to fulfill } \\
\text { meaningful use criteria, even if not directly beneficial to patient care (and at times not even appropriate } \\
\text { for specific patients). More time chipping away at our } 15 \text { min visit. The result; less time to actually see the } \\
\text { patient and care for the patient. A tale that is becoming as old as time }\end{array}$ \\
\hline Medical specialty & $\begin{array}{l}\text { Meaningful use has only reduced the efficiency with which providers can see their patients. Forcing us to } \\
\text { check off certain boxes and fulfill the various criteria of meaningful use does not leave any time to treat } \\
\text { the patients. For example, forcing physicians to enter } 30 \% \text { of radiology orders does nothing to improve } \\
\text { patient care and shifts the workload from nurses and admin staff to the already overworked physicians }\end{array}$ \\
\hline Medical specialty & $\begin{array}{l}\text { It is ridiculous to ask us to care for very complex patients and provide them with the personal attention } \\
\text { they need, including looking at them while we talk, and expect us to fill out all these required fields and } \\
\text { check all these boxes. Because I think it is more important to look at the patient than at the computer } \\
\text { screen, I spend on average } 30 \text { min in addition to direct time with each patient just to complete my note } \\
\text { and checkboxes. This is terribly inefficient }\end{array}$ \\
\hline Medical specialty & $\begin{array}{l}\text { Meaningful use } 1 \text { had many features that are useful for actual patient care: e-prescribing, and maintaining } \\
\text { a problem list being the most useful. Meaningful use } 2 \text { seems to address the administrative issue and not } \\
\text { clinical ones, I have honestly not found the elements very helpful, and some take longer and make no } \\
\text { difference in terms of article use (like the end of the visit, where a form still needs to be printed). I have } \\
\text { found that people sometimes enter misleading or incorrect information to meet the goals, for example, } \\
\text { they would not enter the correct diagnosis when it is a rare one, but something similar and this can lead to } \\
\text { errors in management because it is easy to copy. What would work better is a way to pull all needed } \\
\text { information for a prior authorization for MRIs, sleep studies, and medications-this would actually } \\
\text { improve efficiency, meaningful use } 2 \text { does not }\end{array}$ \\
\hline Surgical specialty & $\begin{array}{l}\text { While I am a strong early-adopter and very tech savvy, the implementation of MU is adding many hours to } \\
\text { my very full schedule. Too much of it is adding time without adding value. Much of it may help a primary } \\
\text { care practice, but not a surgical practice }\end{array}$ \\
\hline Surgical specialty & $\begin{array}{l}\text { The way meaningful use is being rolled out is quite incompetent; the metrics fall way short of improving } \\
\text { patient care. Instead, it is a ton of administrative work that detracts from patient care. It is like asking the } \\
\text { pilot to scrub the floor rather than flying the plane }\end{array}$ \\
\hline Surgical specialty & $\begin{array}{l}\text { Meaningful use is a one-size fits all top-down mandate from Washington with punitive measures if you do } \\
\text { not comply. Small pieces of it are helpful, but most of MU is a workflow killer that does not provide any } \\
\text { patient benefit. It turns the physician into a data entry machine }\end{array}$ \\
\hline
\end{tabular}

Abbreviations: MRI, magnetic resonance imaging; MU, meaningful use; $\mathrm{PCP}$, primary care physician.

patient-centered care. Respondents who saw 30 or fewer outpatients per week had more positive beliefs than respondents who saw more than 30 outpatients per week. For example, $23.4 \%$ of respondents who saw 30 or fewer outpatients per week agreed or strongly agreed that the meaningful use of the EHR would improve quality of care compared with $17.5 \%$ of respondents who saw more than 30 outpatients per week $(p=0.02)$. Practice size was not associated with beliefs except for the belief that the meaningful use of the EHR will not improve patient outcomes. Satisfaction with outpatient EHR was significantly associated with all the beliefs: Physicians in the satisfied group had more positive beliefs about the meaningful use of the EHR.

\section{Self-Efficacy}

Self-efficacy for achieving stage 2 of the meaningful use of the EHR incentive program (defined as moderately confident to extremely confident) was not related to demographic variables (gender, age, and race) (-Table 6). In the case of practice characteristics, number of outpatients seen per week, number of outpatient hours worked per week, and practice size were not associated with self-efficacy. Physician specialty was associated with self-efficacy: $68.1 \%$ of primary care physicians reported self-efficacy for achieving stage 2 of the meaningful use of the EHR incentive program compared with $56.5 \%$ of medical specialists and $44.6 \%$ of surgical specialists $(p<0.001)$. Self-efficacy was also significantly related to satisfaction with the outpatient EHR. More than two-thirds of respondents (67.5\%) who were satisfied with the outpatient EHR reported self-efficacy for achieving stage 2 meaningful use compared with $49.1 \%$ in the other group ( $p<0.001$ ). Self-efficacy was significantly associated with all the belief items except for the belief that the meaningful use of the EHR will improve patient-centered 
Table 5 Physician and practice characteristics and beliefs about the meaningful use of the EHR (percent of respondents)

\begin{tabular}{|c|c|c|c|c|c|c|c|}
\hline \multirow[t]{2}{*}{$\begin{array}{l}\text { Physician and } \\
\text { practice } \\
\text { characteristics }\end{array}$} & $\begin{array}{l}\text { Decrease } \\
\text { medical } \\
\text { errors }\end{array}$ & $\begin{array}{l}\text { Not increase } \\
\text { efficiency } \\
\text { of care }\end{array}$ & $\begin{array}{l}\text { Improve } \\
\text { patient- } \\
\text { centered } \\
\text { care }\end{array}$ & $\begin{array}{l}\text { Not improving } \\
\text { patient } \\
\text { outcomes }\end{array}$ & $\begin{array}{l}\text { Improving } \\
\text { quality } \\
\text { of care }\end{array}$ & $\begin{array}{l}\text { Improving care } \\
\text { personally } \\
\text { delivers }\end{array}$ & $\begin{array}{l}\text { Improving } \\
\text { care the } \\
\text { AMC delivers }\end{array}$ \\
\hline & \multicolumn{7}{|c|}{ (Agree or strongly agree) } \\
\hline \multicolumn{8}{|l|}{ Gender } \\
\hline Female & 31.7 & 61.3 & 20.6 & $33.3^{\mathrm{a}}$ & 19.9 & 20.7 & 24.4 \\
\hline Male & 29.5 & 64.3 & 21.2 & $\begin{array}{l}41.1 \\
(p=0.009)\end{array}$ & 20.0 & 20.9 & 26.0 \\
\hline \multicolumn{8}{|l|}{ Age } \\
\hline$<55 \mathrm{y}$ & 28.8 & 64.4 & 19.7 & 37.4 & 18.8 & 19.8 & 24.4 \\
\hline$\geq 55 y$ & 33.2 & 60.8 & 22.7 & 38.2 & 23.1 & 22.4 & 26.2 \\
\hline \multicolumn{8}{|l|}{ Race } \\
\hline Non-White & 35.5 & 59.4 & 25.4 & 32.1 & $26.2^{\mathrm{b}}$ & $29.1^{c}$ & $31.6^{\mathrm{a}}$ \\
\hline White & 29.6 & 63.4 & 20.1 & 38.1 & $\begin{array}{l}19.5 \\
(p=0.04)\end{array}$ & $\begin{array}{l}19.3 \\
(p=0.003)\end{array}$ & $\begin{array}{l}24.3 \\
(p=0.036)\end{array}$ \\
\hline \multicolumn{8}{|l|}{ Specialty } \\
\hline Primary care & $36.6^{a}$ & 60.0 & 23.4 & $31.5^{\mathrm{a}}$ & $24.6^{b}$ & 21.8 & 26.9 \\
\hline $\begin{array}{r}\text { Medical } \\
\text { specialties }\end{array}$ & 31.2 & 61.9 & 20.1 & 37.0 & 20.9 & 21.7 & 26.2 \\
\hline $\begin{array}{r}\text { Surgical } \\
\text { specialties }\end{array}$ & $\begin{array}{l}19.0 \\
(p=0.001)\end{array}$ & 70.9 & 21.0 & $\begin{array}{l}48.1 \\
(p=0.005)\end{array}$ & $\begin{array}{l}13.3 \\
(p=0.027)\end{array}$ & 15.8 & 18.5 \\
\hline \multicolumn{8}{|c|}{ Hours worked outpatient } \\
\hline$\leq 20 \mathrm{~h} / \mathrm{wk}$ & 31.6 & $59.8^{\mathrm{b}}$ & 22.2 & 36.5 & 21.4 & 23.2 & 27.1 \\
\hline$>20 \mathrm{~h} / \mathrm{wk}$ & 29.6 & $\begin{array}{l}67.6 \\
(p=0.011)\end{array}$ & 20.0 & 39.2 & 19.6 & 18.2 & 23.2 \\
\hline \multicolumn{8}{|c|}{ No. of outpatients per week } \\
\hline$\leq 30$ & $34.7^{b}$ & $58.1^{c}$ & 21.6 & $34.0^{\mathrm{a}}$ & $23.4^{\mathrm{b}}$ & $24.4^{\mathrm{a}}$ & $28.9^{\mathrm{a}}$ \\
\hline$>30$ & $\begin{array}{l}25.7 \\
(p=0.002)\end{array}$ & 69.4 & 20.4 & $\begin{array}{l}42.6 \\
(p=0.005)\end{array}$ & $\begin{array}{l}17.5 \\
(p=0.02)\end{array}$ & $\begin{array}{l}17.0 \\
(p=0.004)\end{array}$ & $\begin{array}{l}21.3 \\
(p=0.006)\end{array}$ \\
\hline \multicolumn{8}{|l|}{ Practice size } \\
\hline $1-2$ & 34.4 & 51.5 & 27.3 & $15.6^{\mathrm{b}}$ & 25.0 & 24.2 & 33.3 \\
\hline $3-5$ & 33.9 & 54.9 & 20.4 & 30.6 & 21.6 & 21.2 & 29.2 \\
\hline $6-10$ & 31.9 & 61.7 & 19.6 & 37.0 & 23.4 & 22.3 & 28.0 \\
\hline$\geq 11$ & 28.7 & 65.3 & 20.6 & $\begin{array}{l}40.0 \\
(p=0.02)\end{array}$ & 18.6 & 20.0 & 22.9 \\
\hline \multicolumn{8}{|c|}{ Satisfaction with outpatient EHR } \\
\hline Other & $21.4^{c}$ & $68.0^{c}$ & $16.0^{c}$ & $42.5^{c}$ & $13.7^{c}$ & $12.9^{c}$ & $17.1^{c}$ \\
\hline Satisfied & 42.3 & 56.1 & 27.5 & 30.9 & 29.3 & 31.4 & 35.9 \\
\hline
\end{tabular}

Abbreviations: AMC, academic medical center; EHR, electronic health record.

Note: Only significant $p$ values are shown.

${ }^{a} p<0.01$.

$\mathrm{b}_{p}<0.05$.

${ }^{c} p<0.001$.

care. Across all belief items, more positive beliefs were associated with higher self-efficacy for achieving stage 2 meaningful use. The multivariate logistic regression model found three items to be significant correlates of self-efficacy: Satisfaction with the outpatient EHR (odds ratio [OR]: 2.10, 95\% confidence interval $[\mathrm{CI}]: 1.61,2.75, p<0.001$ ), physician specialty (OR: $1.75,95 \% \mathrm{CI}: 1.24,2.47, p<0.001$ ), and the belief that the meaningful use of the EHR will decrease medical errors (OR: 1.53, 95\% CI: 1.04, 2.24, $p=0.029$ ).

\section{Change in Beliefs and Self-Efficacy from Stage 1 to Stage 2}

We assessed change in beliefs and self-efficacy from stage 1 to stage 2 of the meaningful use of the EHR incentive program; 518 physicians completed both stage 1 and stage 2 meaningful use surveys. Physicians overall reported more negative beliefs in stage 2 as compared with stage 1 across all belief items (-Table 7 ). For example, $28.1 \%$ agreed or strongly agreed that the meaningful use of the EHR would decrease medical errors 
Table 6 Physician and practice characteristics and self-efficacy (percent of respondents)

\begin{tabular}{|c|c|}
\hline $\begin{array}{l}\text { Physician and practice } \\
\text { characteristics }\end{array}$ & $\begin{array}{l}\text { Self-efficacy } \\
\text { (Moderately to } \\
\text { extremely confident) }\end{array}$ \\
\hline \multicolumn{2}{|l|}{ Gender } \\
\hline Female & 59.3 \\
\hline Male & 55.2 \\
\hline \multicolumn{2}{|l|}{ Age } \\
\hline$<55$ y & 57.6 \\
\hline$\geq 55$ y & 55.5 \\
\hline \multicolumn{2}{|l|}{ Race } \\
\hline Non-White & 58.7 \\
\hline White & 57.7 \\
\hline \multicolumn{2}{|l|}{ Specialty } \\
\hline Primary care & $68.1^{\mathrm{a}}$ \\
\hline Medical specialties & 56.5 \\
\hline Surgical specialties & 44.6 \\
\hline \multicolumn{2}{|c|}{ Hours worked outpatient } \\
\hline$\leq 20 \mathrm{~h} / \mathrm{wk}$ & 55.4 \\
\hline$>20 \mathrm{~h} / \mathrm{wk}$ & 58.8 \\
\hline \multicolumn{2}{|c|}{ No. of outpatients per week } \\
\hline$\leq 30$ & 56.7 \\
\hline$>30$ & 58.2 \\
\hline \multicolumn{2}{|l|}{ Practice size } \\
\hline $1-2$ & 51.5 \\
\hline $3-5$ & 56.3 \\
\hline $6-10$ & 62.4 \\
\hline$\geq 11$ & 55.2 \\
\hline \multicolumn{2}{|c|}{ Satisfaction with outpatient EHR } \\
\hline Other & $49.1^{\mathrm{a}}$ \\
\hline Satisfied & 67.5 \\
\hline
\end{tabular}

Abbreviation: EHR, electronic health record. Note: Only significant $p$ values are shown. ${ }^{\mathrm{a}} \mathrm{p}<0.001$.

in stage 2 as compared with $35.9 \%$ in stage $1(p<0.001)$. Primary care physicians reported more negative beliefs in stage 2 as compared with stage 1 ( - Table 7 ). For example, $63 \%$ of primary care physicians agreed or strongly agreed that meaningful use of the EHR would not increase the efficiency of care in stage 2 compared with $46.2 \%$ in stage $1(p<0.001)$. However, self-efficacy for achieving meaningful use did not change from stage 1 to stage 2 .

\section{Discussion}

Only a fifth of the physicians responding to our survey agreed or strongly agreed that the meaningful use of the EHR would improve patient-centered care and the quality of care. A majority of physicians, $62.9 \%$, agreed or strongly agreed that the meaningful use of the EHR would not increase the efficiency of the care they provide. These findings show that physicians continue to express negative beliefs about the meaningful use of the EHR. ${ }^{5-8}$

Also, the beliefs in this follow-up study were even more negative than those found with respect to stage 1 of the meaningful use of the EHR incentive program. ${ }^{8}$ The greater negative beliefs about the meaningful use of the EHR in stage 2 as compared with stage 1 holds true across all the seven beliefs that we examined in our study. One factor that may play a role in these greater negative beliefs is that stage 2 sets more advanced goals than stage 1 as envisioned by the escalator concept of the stages of meaningful use ${ }^{1}$ : it was always expected that stage 2 would be harder to meet than stage 1 , and physicians were expected to meet more requirements in stage 2 than stage 1 . At the same time, physicians receive about $50 \%$ of the incentive for achieving stage 2 that they received in stage $1{ }^{18}$ Also, whether or not the physicians actually receive the incentives personally depends on their departments and hospitals, and varies considerably across institutions.

Among sociodemographic characteristics, we generally did not find gender and age to be associated with beliefs. As in the case of stage 1 our study did not find a difference between physicians 55 years and older and those younger than 55 in either beliefs about the meaningful use of the EHR or selfefficacy for achieving stage 2 of the meaningful use of the EHR incentive program although studies have reported that younger physicians are more likely adopt EHRs and be ready for meaningful use. ${ }^{14,16}$

The number of hours worked per week was not associated with beliefs but the number of outpatients seen per week was significantly associated with beliefs about the meaning of the EHR for improving the efficiency of care, patient outcomes, quality of care, and the care the physician and the AMC delivers. Physicians who saw 30 or fewer outpatients per week had significantly greater positive beliefs in these areas than physicians who saw more than 30 outpatients per week. This suggests that physician workload may play an important role in influencing attitudes and beliefs about the meaningful use of the EHR. Several studies have proposed initiatives, such as workflow help and practice redesign to support physician workload. ${ }^{7,16,19}$ The NCQA (National Committee for Quality Assurance) patient-centered medical home certification was one of the strongest predictors of progress toward meaningful use in one study. ${ }^{16}$ More specifically, a group health study on meaningful use reported that the patient-centered medical home was used to reduce the number of patients seen by primary care physicians. ${ }^{19}$ Such initiatives which affect physician workload are likely to play an important role in influencing positive beliefs about the meaningful use of the EHR among primary care physicians. At the same time, similar initiatives need to be developed for medical and surgical specialists who have expressed concerns about participation in the meaningful use program and whether EHRs can be meaningfully used in their areas. ${ }^{8,9}$

We found physician specialty was associated with some beliefs but not others. Physician specialty was associated 
Table 7 Change in beliefs from stage 1 to stage 2 meaningful use (percent respondents)

\begin{tabular}{|c|c|c|c|c|}
\hline & \multicolumn{2}{|c|}{$\begin{array}{l}\text { All respondents } \\
(n=518)\end{array}$} & \multicolumn{2}{|c|}{$\begin{array}{l}\text { Primary care } \\
\text { physicians }(n=129)\end{array}$} \\
\hline & Stage 1 & Stage 2 & Stage 1 & Stage 2 \\
\hline & \multicolumn{4}{|c|}{ (Agree or strongly agree) } \\
\hline \multicolumn{5}{|l|}{ Beliefs } \\
\hline Decrease medical errors & 35.9 & $28.1^{\mathrm{a}}$ & 42.0 & $33.3^{b}$ \\
\hline Not increase efficiency of care & 44.3 & $67.5^{*}$ & 46.2 & $63.0^{\mathrm{a}}$ \\
\hline Improve patient-centered care & 27.4 & $20.0^{a}$ & 37.8 & $25.2^{\mathrm{a}}$ \\
\hline Not improve patient outcomes & 28.1 & $44.1^{\mathrm{a}}$ & 18.1 & $35.3^{a}$ \\
\hline Improve quality of care & 24.7 & $18.4^{\mathrm{a}}$ & 33.6 & $22.0^{\mathrm{a}}$ \\
\hline Improve care personally delivers & 20.8 & $17.8^{\mathrm{a}}$ & 27.7 & $18.6^{\mathrm{b}}$ \\
\hline Improve care the AMC delivers & 36.7 & $21.5^{\mathrm{a}}$ & 41.2 & $22.6^{a}$ \\
\hline Self-efficacy (moderately confident to extremely confident) & 58.1 & 57.3 & 60.0 & 66.1 \\
\hline
\end{tabular}

Abbreviation: AMC, academic medical center.

${ }^{\mathrm{a}} \mathrm{p}<0.001$.

${ }^{\mathrm{b}} p<0.01$.

with beliefs that the meaningful use of the EHR will improve quality of care, decrease medical errors, and improve patient outcomes. Primary care physicians had more positive beliefs in these areas than specialists as we and others have reported. ${ }^{8,20}$ However, physician specialty was not associated with beliefs that the meaningful use of the EHR will improve the efficiency of care, patient-centered care or the care the physician and organization deliver. Moreover, our study found that the gap between primary care physicians and specialists decreased with respect to these beliefs as primary care physicians reported greater negative beliefs about the meaningful use of the EHR in response to stage 2. As previously noted, and as the comments in - Table 4 illustrate, the greater number of requirements in stage 2 could be one contributing factor to these greater negative beliefs. Another factor that could influence the greater negative beliefs among primary care physicians in stage 2 are the criteria related to patient engagement whose achievement falls to a large extent on such physicians. In a study examining physician perceptions and beliefs about one of these criteria, the provision of the AVS to patients, we found that a majority of primary care physicians (79\%) reported a negative effect of the provision of the AVS on workload. ${ }^{9}$

Finally, physician satisfaction with the outpatient EHR was significantly associated with all the beliefs, with physicians in the satisfied group reporting more positive beliefs about the meaningful use of the EHR. Physician satisfaction with the outpatient EHR also emerged as the most significant predictor of self-efficacy in our multivariate model. Physicians who were satisfied with the EHR were two times more likely to have selfefficacy for achieving stage 2 of the meaningful use of the EHR incentive program. Physician satisfaction with the EHR appears to be an important factor in beliefs and self-efficacy at a global level as found in our studies as well as with respect to the specific functionality of the EHR. Makam et $\mathrm{al}^{21}$ found variations in satisfaction with key EHR functionality and concluded that dissatisfaction with and suboptimal use of such key functionality might in part explain the lack of association between EHR use and quality of care.

\section{Limitations}

This study was conducted in the setting of two AMCs in one region. Thus, the study findings may not apply to other settings, including different practice types or regions. However, many of the physicians evaluated do practice in the community setting. Our study focused on beliefs captured as outcome expectancies, but it is troubling that the beliefs were not more positive. Other types of beliefs could also be examined, including beliefs about controllability and normative beliefs. ${ }^{22}$ Another limitation of the study was that the response rate of the survey was just over half (52.9\%) and the physicians who responded to our survey may have stronger negative beliefs than those who chose not to respond to the survey. Finally, the study also did not include factors, such as physician expectations of EHRs, which may also impact beliefs and self-efficacy ${ }^{23}$ and did not assess outcomes which may or may not be correlated with beliefs.

\section{Conclusion}

We conducted a follow-up survey of physician beliefs about the meaningful use of the EHR. We found that physicians continue to have negative beliefs about the meaningful use of the EHR in very important domains including efficiency, patient-centeredness, and quality of care, and that these negative beliefs have increased from stage 1 to stage 2 of the meaningful use of the EHR incentive program. These findings potentially represent a barrier to the meaningful use of the EHR, and more broadly to improving quality, safety, and efficiency with EHRs. If negative beliefs about the meaningful use of the EHR persist and grow, the escalator approach to implementing the meaningful use of 
the EHR incentive program as well as the speed of the escalator will be impacted. One study found that active users of the meaningful use program are dropping out of the program frustrated by the effort required compared with the incentive offered for achieving meaningful use. ${ }^{7}$

With respect to the role of physician specialty in meaningful use, two findings emerged from this follow-up study that can be of relevance to practitioners. The gap between primary care physicians and specialists in beliefs about the meaningful use of the EHR decreased as primary care physician beliefs grew more negative from stage 1 to stage 2. It is possible that this finding is specific to the physicians in our study. However, we suspect that other health care settings may see the development of more negative beliefs among primary care physicians given the increasing requirements of meaningful use from one stage to the next. At the same time, primary care physicians had greater selfefficacy than specialists for achieving stage 2 meaningful use. This is not surprising, as primary care physicians have been using EHRs much more intensively and longer than specialists, who are finding meaningful use to be much more disruptive to existing workflows. ${ }^{24}$ To enhance selfefficacy among specialists, interventions, such as feedback on individual performance and interactive continuing medical education (CME) that focuses on skill development could be deployed. ${ }^{25}$

This study, and others we have conducted, ${ }^{8,9}$ found physician satisfaction with the EHR to be an important factor in beliefs about the meaningful use of the EHR and self-efficacy for achieving meaningful use. This suggests the importance of enhancing physician satisfaction with the EHR for successful implementation of the meaningful use of the EHR incentive program. Physicians can play an important role in this process by suggesting improvements and enhancements in the key functionality of the EHR. ${ }^{21}$ Finally, we suggest the inclusion of physician experience with EHRs, such as physician satisfaction with the use of EHRs, in evaluations of meaningful use similar to a proposal for the inclusion of patient experience in meaningful use. $^{19}$

\section{Clinical Relevance Statement}

Given that few physicians had positive beliefs about the meaningful use of the EHR, and that negative beliefs may be growing, we suggest that organizations should devote strategies and resources to promote positive beliefs about the meaningful use of the EHR among all physicians (and not just specialists). As the growing literature on this subject suggests, there does not appear to be one fix to the problem. Instead, a range of strategies will need to be adopted such as practice and workflow redesign, enhancement of EHR functionality as needed, training, collaborative learning sessions and practice improvement advice, and audit and feedback of individual performance around the criteria for becoming a meaningful user of the EHR. Physicians can provide valuable input into the suite of strategies that best fit practices and providers, reduce physician workload and increase the effectiveness of care and the care the physician delivers. ${ }^{26,27}$

\section{Multiple Choice Questions}

1. The escalator concept of meaningful use refers to:

A. The three stages of the meaningful use of the EHR incentive program

B. Providing incentives to physicians to participate in the meaningful use of the EHR incentive program

C. A staged approach toward achieving the final goals of the Meaningful use of the EHR incentive program

D. Differential beliefs about meaningful use of the EHR among primary care physicians and specialists

Correct Answer: The correct answer is C. A staged approach to achieving the goals of the meaningful use of the EHR incentive program has been considered analogous to the concept of an escalator. ${ }^{1}$ With each stage, the notion has been that providers would move upward toward the final goal of achieving improvement in quality, safety, and efficiency of care. ${ }^{2}$

2. In this study the strongest predictor of self-efficacy for achieving stage 2 of the meaningful use of the EHR incentive program was:

A. Physician specialty

B. Practice size

C. Number of outpatients seen per week

D. Physician satisfaction with outpatient EHR

Correct Answer: The correct answer is D. The multivariate logistic regression model found three items to be significant predictors of self-efficacy for achieving stage 2 of the meaningful use of the EHR incentive program, of which the strongest predictor was physician satisfaction with the outpatient EHR: physician satisfaction with the outpatient EHR (OR: 2.10, 95\% CI: $1.61,2.75, p<0.001$ ), physician specialty (OR: 1.75 , 95\% CI: $1.24,2.47, p<0.001$ ), and the belief that the meaningful use of the EHR will decrease medical errors (OR: 1.53, 95\% CI: 1.04, 2.24, $p=0.029$ ).

\section{Protection of Human and Animal Subjects}

The study was performed in compliance with the World Medical Association Declaration of Helsinki on ethical principles for medical research involving human subjects, and was reviewed by the Partners HealthCare institutional review board.

Conflict of Interest

None.

\section{References}

1 Blumenthal D, Tavenner M. The "meaningful use" regulation for electronic health records. N Engl J Med 2010;363(06):501-504

2 Buntin MB, Jain SH, Blumenthal D. Health information technology: laying the infrastructure for national health reform. Health Aff (Millwood) 2010;29(06):1214-1219

3 Linder JA, Ma J, Bates DW, Middleton B, Stafford RS. Electronic health record use and the quality of ambulatory care in the United States. Arch Intern Med 2007;167(13):1400-1405 
4 Samal L, Wright A, Healey MJ, Linder JA, Bates DW. Meaningful use and quality of care. JAMA Intern Med 2014;174(06):997-998

5 Grabenbauer L, Fraser R, McClay J, et al. Adoption of electronic health records: a qualitative study of academic and private physicians and health administrators. Appl Clin Inform 2011;2 (02):165-176

6 Grabenbauer L, Skinner A, Windle J. Electronic health record adoption-maybe it's not about the money: physician super-users, electronic health records and patient care. Appl Clin Inform 2011; 2(04):460-471

7 Weeks DL, Keeney BJ, Evans PC, Moore QD, Conrad DA. Provider perceptions of the electronic health record incentive programs: a survey of eligible professionals who have and have not attested to meaningful use. J Gen Intern Med 2015;30(01):123-130

8 Emani S, Ting DY, Healey M, et al. Physician beliefs about the impact of meaningful use of the EHR: a cross-sectional study. Appl Clin Inform 2014;5(03):789-801

9 Emani S, Ting DY, Healey M, et al. Physician perceptions and beliefs about generating and providing a clinical summary of the office visit. Appl Clin Inform 2015;6(03):577-590

10 Jha AK. Meaningful use of electronic health records: the road ahead. JAMA 2010;304(15):1709-1710

11 Abbett SK, Bates DW, Kachalia A. The meaningful use regulations in information technology: what do they mean for quality improvement in hospitals? Jt Comm J Qual Patient Saf 2011;37(07): 333-336, 289

12 Hogan SO, Kissam SM. Measuring meaningful use. Health Aff (Millwood) 2010;29(04):601-606

13 Hsiao CJ, Decker SL, Hing E, Sisk JE. Most physicians were eligible for federal incentives in 2011, but few had EHR systems that met meaningful-use criteria. Health Aff (Millwood) 2012;31(05):1100-1107

14 Decker SL, Jamoom EW, Sisk JE. Physicians in nonprimary care and small practices and those age 55 and older lag in adopting electronic health record systems. Health Aff (Millwood) 2012; 31(05):1108-1114

15 Xierali IM, Phillips RL Jr, Green LA, Bazemore AW, Puffer JC. Factors influencing family physician adoption of electronic health records (EHRs). J Am Board Fam Med 2013;26(04):388-393
16 Heisey-Grove D, King JA. Physician and practice-level drivers and disparities around meaningful use progress. Health Serv Res 2017;52(01):244-267

17 Hosmer DW, Lemeshow S. Special Topics. In: Applied Logistic Regression, Second Edition. Hoboken, NJ: John Wiley \& Sons, Inc.; 2000

18 Mitchell J, Waldren SE. Making sense of meaningful use stage 2: second wave or tsunami? Fam Pract Manag 2014;21(01):19-24

19 Ralston JD, Coleman K, Reid RJ, Handley MR, Larson EB. Patient experience should be part of meaningful-use criteria. Health Aff (Millwood) 2010;29(04):607-613

20 DesRoches CM, Audet A-M, Painter M, Donelan K. Meeting meaningful use criteria and managing patient populations: a national survey of practicing physicians. Ann Intern Med 2013;158(11): 791-799

21 Makam AN, Lanham HJ, Batchelor K, et al. Use and satisfaction with key functions of a common commercial electronic health record: a survey of primary care providers. BMC Med Inform Decis Mak 2013;13:86

22 Bandura A. Self-efficacy: toward a unifying theory of behavioral change. Psychol Rev 1977;84(02):191-215

23 Zandieh SO, Abramson EL, Pfoh ER, Yoon-Flannery K, Edwards A, Kaushal R. Transitioning between ambulatory EHRs: a study of practitioners' perspectives. J Am Med Inform Assoc 2012;19(03): 401-406

24 Chiang MF, Boland MV, Brewer A, et al; American Academy of Ophthalmology Medical Information Technology Committee. Special requirements for electronic health record systems in ophthalmology. Ophthalmology 2011;118(08):1681-1687

25 Cabana MD, Kim C. Physician adherence to preventive cardiology guidelines for women. Womens Health Issues 2003;13(04):142-149

26 Fernald DH, Wearner R, Dickinson WP. The journey of primary care practices to meaningful use: a Colorado Beacon Consortium study. J Am Board Fam Med 2013;26(05):603-611

27 Shea CM, Reiter KL, Weaver MA, et al. Stage 1 of the meaningful use incentive program for electronic health records: a study of readiness for change in ambulatory practice settings in one integrated delivery system. BMC Med Inform Decis Mak 2014;14:119 